\title{
A connected glass community
}

\author{
M. Overend $₫$ - J. Belis $₫$ - C. Louter $(\mathbb{D}$ - \\ J. H. Nielsen 1 J. Schneider $(\mathbb{D}$
}

Published online: 17 December 2021

(C) The Author(s), under exclusive licence to Springer Nature Switzerland AG 2021

As 2021 comes to a close and the world stutters to emerge from the global pandemic, the GS\&E editorial team have been busy setting up new ways of disseminating and celebrating the leading edge research and ground breaking practical applications in the field of glass structures, namely:

- We have now completed our 3rd Glassinars event. They have been so well received that we are planning a new round of online presentations for 2022.

M. Overend $(\varangle)$

Faculty of Architecture and the Built Environment, Delft University of Technology, Delft, The Netherlands e-mail: m.overend@tudelft.nl

\section{J. Belis}

Department of Structural Engineering, Ghent University, Ghent, Belgium

e-mail: jan.belis@ugent.be

C. Louter

Institute of Building Construction, Technische Universität Dresden, Dresden, Germany

e-mail: christian.louter@tu-dresden.de

http://bauko.bau.tu-dresden.de

J. H. Nielsen

Department of Civil Engineering, Technical University of Denmark, Kgs. Lyngby, Denmark

e-mail: jhn@byg.dtu.dk

https://www.glass.byg.dtu.dk/

J. Schneider

Institute of Structural Mechanics and Design, Technische Universität Darmstadt, Darmstadt, Germany

e-mail: schneider@ismd.tu-darmstadt.de
Further details on the upcoming Glassinars and access to playbacks of past Glassinars are now available. Join us!

- The GS\&E journal is now active on several social media channels. In addition to LinkedIn we are now on Twitter, Instagram and Youtube. Follow us!

- We are lining up special GS\&E issues on topical subjects, namely: Glass Design Codes; Glass \& Extreme Events; Glass Circularity; Glass \& Digital Transformation. Submit your paper!

- The best paper award has just been announced. The best paper published in 2020 went to Telesilla Bristogianni, Faidra Oikonomopoulou, Rong Yu, Fred A. Veer \& Rob Nijsse for their paper "Investigating the flexural strength of recycled cast glass". Many congratulations!

Further information on these initiatives is available on the journal homepage (https://www.springer.com/ journal/40940/updates). We hope they provide means of staying up-to-date and connecting with members of the glass community that would otherwise be impossible in these COVID-restricted times.

All these initiatives stand on the shoulders of the high-quality papers that are published in GS\&E. This issue is no exception. The first three papers deal with improved methods for failure prediction, in particular for cantilevered glass balustrades (Nizich et al.), bi-axially loaded plates (Kinsella et al.) and glass exposed to solar radiation (Galuppi et al.). The second set of papers involves experimental investiga- 
tions on ways of improving the performance of glass structures, specifically by durable coatings (Corrado et al.), in laminated glass beams (Cabeza et al.) and by liquid lamination of embedded connections (Volakos et al.).
Enjoy reading!

Publisher's Note Springer Nature remains neutral with regard to jurisdictional claims in published maps and institutional affiliations. 